Shelton, D.R. and M.L. Lacy. 1980. Effect of harvest duration on yield and on depiction of storage carbohydrates in asparagus roots. J. Amer. Soc. Hort. Sci. 105(3):332-335.
Yeager, A.F. and D.H. Scott. 1939. Studies of mature asparagus plantings with special reference to sex survival and rooting habits. Proc. Amer. Soc. Hort. Sci. 36:513-514.
Young, R.E. 1940. The depth of planting asparagus and its effect on stand, yield and position of the crown. Proc. Amer. Soc. Hort. Sci. 37:783-784.

\section{Annual and Biennial Pruning of Mature Lateral-bearing English Walnuts}

\author{
William H. Olson', D.E. Ramos ${ }^{2}$, K. Ryugo ${ }^{3}$, and R.G. Snyder ${ }^{4}$ \\ Cooperative Extension, University of California, Davis, CA 95616
}

Additional index words. light penetration, pruning, yield, quality

\begin{abstract}
Annual pruning was compared with nonpruning for 8 years and to two biennial pruning treatments for 4 years in a mature full-canopied 'Ashley' walnut (Juglans regia L.) orchard. Light penetration and nut distribution through the canopy was improved by pruning. Nut size and percent edible kernel was consistently lower in nonpruned trees than in trees pruned annually or biennially. Yield from annually pruned trees was not significantly different from that of the nonpruned trees because of the removal of fruitful spurs. Yield of biennially pruned trees was similar to annually pruned or nonpruned trees in the year following pruning, but yield was usually greater during years in which trees were not pruned.
\end{abstract}

Lateral-bearing English walnut orchards in California are commonly planted at a density of 120 trees/ha. The foliar canopy of these trees, trained to a modified central leader, covers the orchard floor within 10 to 12 years (Ryugo et al., 1980). Once this crowded condition occurs, spurs in the lower part of the tree lose their vitality and die, ultimately resulting in dead branches in the lower-canopy and an elevated bearing area. As the bearing area moves upward, the trees become larger, leading to poor spray coverage and increased pruning labor.

In these mature, crowded orchards, a treethinning system is sometimes practiced, whereby alternate, temporary trees are gradually pruned to provide room for -the expanding permanent trees (Martin, 1971). Eventually these temporary trees are removed, leaving about half of the original trees, depending on the thinning arrangement. Thinning walnut orchards in California is not a popular cultural practice because of the uncertainties of regaining production and the threat of fatal tree diseases on the remaining trees, which could reduce yields.

A second option to maintain tree size and vigor is an intense annual pruning program. However, growers question the value of pruning walnut trees because of the amount

Received for publication 30 June 1989. The cost of publishing this paper was defrayed in part by the payment of page charges. Under postal regulations, this paper therefore must be hereby marked advertisement solely to indicate this fact.

'Coopertative Extension Farm Advisor, 2279 Del

Oro Ave., Suite B, Oroville, CA 95965.

${ }^{2}$ Cooperative Extension Pomologist.

${ }^{3}$ Pomologist.

${ }^{4}$ Pomology Staff Research Associate. of labor and equipment required. No pruning, a third alternative, compounds the crowding problem and leads to reduction in nut size similar to that reported for pecan (Crane, 1932, 1933; Hardy, 1947; Hinrichs, 1965).

The objectives of this experiment were to: 1) evaluate annual pruning compared with no pruning and 2) evaluate biennial pruning as a possible method to reduce labor requirements and, yet, control tree size, sustain crop production, and improve nut quality.

The experiment was initiated in 1978 near Gridley, Calif., in an orchard of uniform 16year-old 'Ashley' walnut trees, a very precocious cultivar. Trees were spaced $9.1 \times$ $9.1 \mathrm{~m}$ and grown in Columbia fine sandy loam soil (Carpenter et al., 1926). Columbia soils are coarse-loamy, mixed, nonacid, thermic, Aquic Xerofluvents. Pretreatment 1980 and 1981. yield, nut quality, and cross-sectional trunk area measurements were taken in 1977 to establish the uniformity of the trial. The experimental design was a randomized complete block and began with two treatments: annual pruning and nonpruning. The two treatments were replicated four times with 48 trees per plot until 1982. In 1982, the trial was redesigned with the addition of two new treatments: biennial pruning (even years) and biennial pruning (odd years). The plot size of the original two treatments started in 1978 was reduced to 12 trees per plot and the two biennial pruning treatments were added, each replicated four times with 12 trees per plot. The new treatments were randomized, with respect to the previous existing treatments. These four treatments were maintained through 1985. Throughout the experiment, guard trees surrounding each plot were pruned similarly to eliminate border effects. Selective limb pruning of all treatments was performed in January or February of each year. The objectives of the pruning were to: 1) keep trees from interfering and shading each other; 2) keep tree centers somewhat open; 3) control tree height; 4) replace old, nonvigorous fruitwood with younger, vigorous fruitwood; and 5) thin-out crowded zones within the trees. These objectives were accomplished by making $\approx 37$ thinning-type pruning cuts on each pruned tree each year. Most branches eliminated were $<38 \mathrm{~mm}$ in diameter, but some were as large as $68 \mathrm{~mm}$ in diameter at the base. Fresh weights of prunings were taken each year on the same 10 trees per plot through 1981 and on the same three trees per plot from 1982 through 1985.

Each year, composite yields from the 48or 12-tree plots were taken and six 500-g walnut subsamples were taken from each plot for quality analysis until 1982, when the

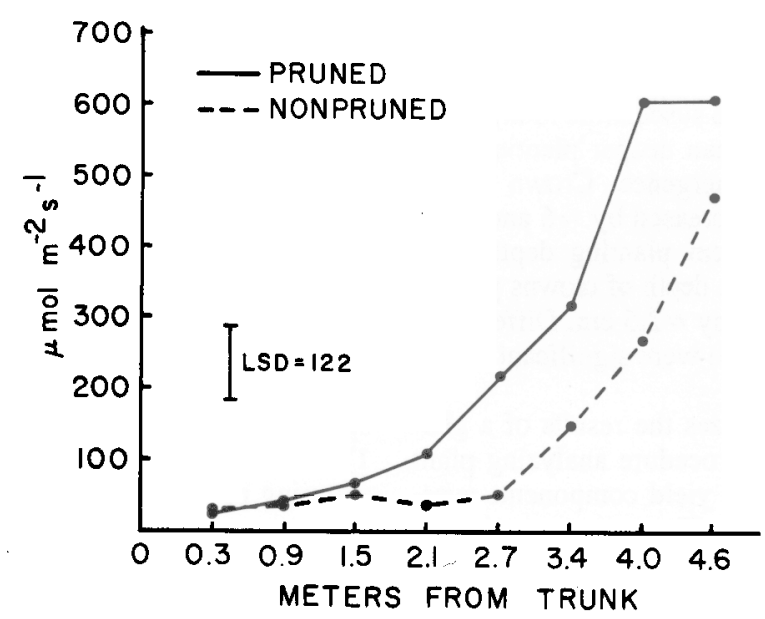

Fig. 1. Effect of pruning on mean photosynthetic photon flux with distance from trunk. Means for 
Table 1. Effect of pruning on yield, nut size, and edible kernel of mature 'Ashley' walnuts.

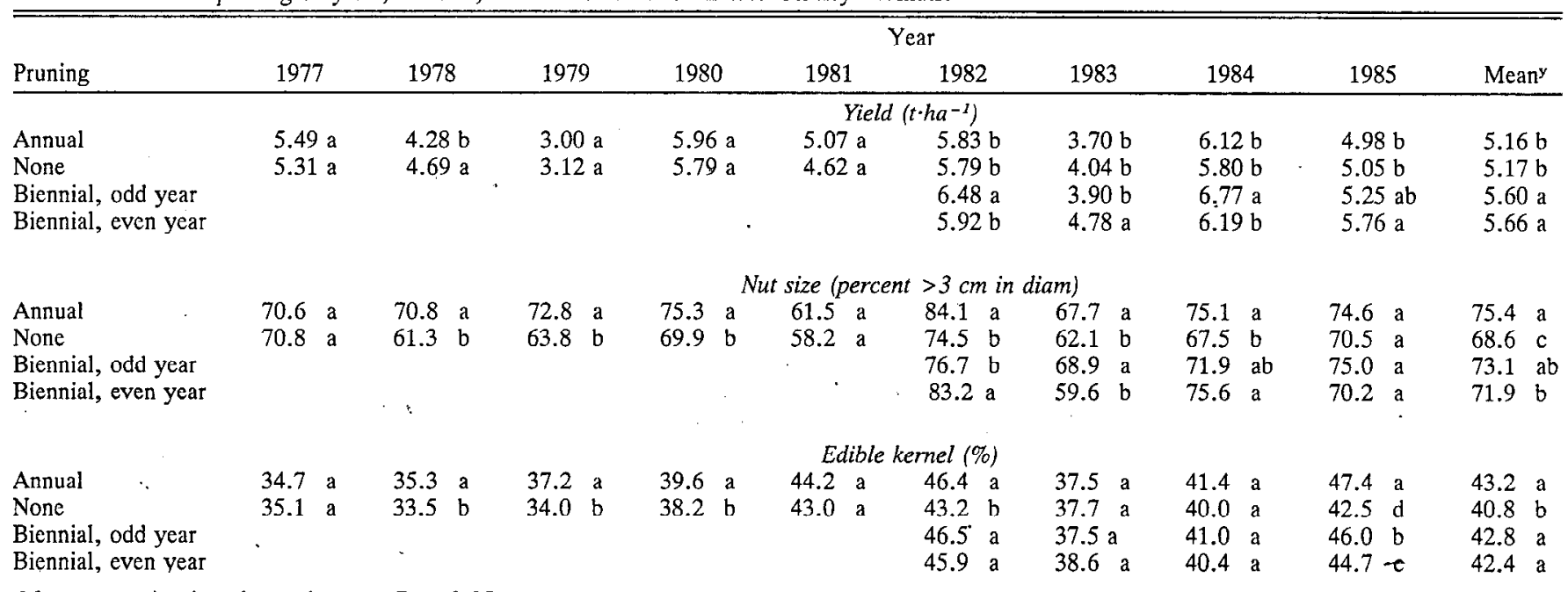

${ }^{2}$ Mean separation in columns by LSD, $P=0.05$.

yMeans based on years 1982-85.

Table 2. Percentage of fruitful shoots measured on three equal segments of one scaffold branch per tree, $2.5 \mathrm{~m}$ above the ground, five trees per replication.

\begin{tabular}{lccc}
\hline & \multicolumn{1}{c}{ Fruitful shoots $(\%)^{\mathrm{z}, \mathrm{y}}$} \\
\cline { 2 - 4 } Pruning & Scaffold branch segment & Terminal \\
Annual & $27.7 \mathrm{a}$ & Mid & $43.2 \mathrm{a}$ \\
None & $17.5 \mathrm{~b}$ & $27.4 \mathrm{a}$ & $33.0 \mathrm{a}$ \\
\hline
\end{tabular}

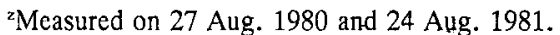

yMean separation in columns by Fisher's F test, $P=0.05$.

number of subsamples was reduced to four per plot. Diamond Walnut Growers of Stockton, Calif., evaluated the quality of the walnut samples based on the following criteria: large walnuts, kernel color, edible kernel, internal and external damage, and offgrade (Diamond Walnut Growers, 1987).

Photosynthetic photon flux (PPF) measurements on five pruned and nonpruned trees per plot were taken on two cloudless days (27 Aug. 1980 and 24 Aug. 1981) to evaluate the effect of pruning. Measurements were taken between 1230 and 1300 HR with a portable Lambda light meter (model LI 185A, Lincoln, Neb.) and Lambda quantum sensor (model LI 191S) 1.m above the ground on an east-west transect at $0.60-\mathrm{m}$ intervals through the canopy, starting $0.30 \mathrm{~m}$ from the trunk. The data for the two years were averaged and analyzed by analysis of variance (ANOVA).

In 1980 and 1981, the number of fruitful and vegetative shoots were determined on one scaffold branch $\approx 2.5 \mathrm{~m}$ above the ground on five pruned and five nonpruned trees per replication. For comparison, each scaffold branch was partitioned into three equal segments: basal, mid, and terminal. The average percentage of fruitful shoots on each segment of the scaffold branch was analyzed by ANOVA.

Cross-sectional tree trunk area measurements (data not presented), pretreatment (1977) yield, percentage large nuts (larger than $3 \mathrm{~cm}$ in diameter), and percentage edible kernel (whole or parts of kernels free of offgrade) measurements (Table 1) indicated that this was a very uniform orchard and suitable for pruning studies.

Fresh pruning weights from the annually pruned trees averaged $37.0 \pm 12.2 \mathrm{~kg} /$ tree removed in 1978 and 1979 and $19.0 \pm 7.0$ $\mathrm{kg} /$ tree during 1980 through 1985 . Pruning weights from the biennial treatments averaged $29.3 \pm 7.8 \mathrm{~kg}$ for the trees pruned in odd years, and the even years averaged 27.5 $\pm 7.6 \mathrm{~kg}$.

There were no significant differences in PPF among the east and west sides of annually pruned or nonpruned trees (data not shown). However, the interaction among annually pruned vs. nonpruned trees by distance from trunks was highly significant (Fig. 1). PPF increased more rapidly toward the canopy periphery in annually pruned trees than nonpruned trees. Beginning at $2.4 \mathrm{~m}$ from the trunk, toward the canopy, PPF was greater when pruned annually.

The percentage of fruitful shoots was significantly greater on the basal and mid-segments of scaffold branches on annually pruned than on nonpruned trees (Table 2). Differences in the percentage of fruitful shoots on the terminal segment of the scaffold branches among the two treatments were not significant.

Yield from nonpruned trees was not significantly different from that of annually pruned trees for the 8 years of the experiment, with the exception of 1978, when yield of nonpruned trees was greater than that of annually pruned trees (Table 1). Yield from biennially pruned trees the year following nonpruning was significantly greater than yields from other treatments. Average yield for 4 years from biennially pruned trees was significantly greater than yields from annually pruned or nonpruned trees.

The percentage of large walnuts and percent edible kernel were the only nut quality characteristics showing any significant differences among treatments. Pruning increased nut size in 6 of the 8 years (Table 1). For the final 4 years of the experiment, nut size. was sometimes reduced by biennial pruning, compared with annual pruning, but nuts were larger than when trees were not pruned.

Percent edible kernel was significantly greater in 5 of the 8 years in annually pruned trees, compared with nonpruned trees (Table 1). The percent edible kernel from biennially pruned trees was similar to that of annually pruned trees in 3 of 4 years. In 1985, the percent edible kernel was significantly lower with the biennially pruned trees than with those pruned annually (Table 1).

Heavy pruning reduced yield in the first year of the experiment in the annually pruned treatment, as compared to the nonpruned treatment. Although there was no significant difference in yield between trees pruned annually and trees not pruned from 1979 through 1985, the distribution of fruitful shoots (Table 2) suggests that the nut distribution in the trees was different. Most of the fruitful shoots on nonpruned trees were located on the peripheral third of the branches, while annually pruned trees had more fruitful shoots located on the mid- and basal third of branches than did nonpruned trees. Although the annually pruned trees had larger nuts and a greater edible kernel percentage than the nonpruned trees, this increase in quality was not enough to offset the cost of labor and equipment used in pruning and brush disposal (data not presented).

These findings are in contrast to those of Witt et al. (1989), who projected that revenues from the additional yields due to pruning more than covered the additional cost of pruning pecan trees. However, the pruning in Witt's study was limited to alternate, tem- 
porary trees before their removal.

Pruning results in long, vigorous shoots. In lateral-bearing cultivars, these shoots are capable of producing many nuts during the year after pruning. Our yield data indicate that biennial pruning takes advantage of this bearing habit by allowing maximum production in the year following nonpruning and renewal of fruitwood without sacrificing production in the year following pruning. Although nut quality was highest in the annually pruned treatment, biennial treatments had the highest production. Pruning weights from the biennially pruned trees averaged $\approx 9$ $\mathrm{kg}$ more per tree in the year trees were pruned than the annually pruned trees, but the time involved to prune a hectare of trees was nearly the same (data not presented).

Pruning labor for biennially pruned treatments was half that of annual pruning, since it was done only every other year. The increased production, compared to no pruning, with the moderate reduction in nut quality and half the labor of annual pruning makes biennial pruning of mature lateral-bearing walnut trees. an attractive alternative to annual pruning, and a practice clearly better than continued nonpruning.

Alternate bearing is a concern with alternate-year pruning. In this experiment, we observed that pruning biennially following the years of low production reduced the alternate-bearing tendency, while pruning biennially following the years of high production accentuated it. Kuykendall (1973) and Worley (1984) have reported similar observations with pecan. Consequently, when considering a change to or initiating a biennial pruning program, one should also consider the previous cropping history of the walnut orchard.

\section{Literature Cited}

Carpenter, E. T., A. T. Strahorn, T.W. Glassey, and R.E. Storie. 1926. Columbia loam, p. 2122. In: Sydney Frissell (cd.). Soil survey of the Oroville area, California. USDA Bur. Chemistry and Soils, Washington, D.C.

Crane, H.L. 1932. Two years' results of pruning bearing pecan trees. Proc. Georgia-Florida Pecan Growers Assn. 26:44-51.

Crane, H.L. 1933. Results of pecan pruning experiments: Proc. Georgia-Florida Pecan Growers Assn. 27:11-16.

Diamond Walnut Growers, Inc. 1987. Diamond Walnut Growers inspection manual. (revised 1987.) Diamond Walnut Growers, Stockton, Calif.

Hardy, M.B. 1947. Progress report on attempts to control biennial bearing in pecans. Proc. Southeastern Pecan Growers Assn. 40:54-62.

Hinrichs, H.A. 1965. Pecan investigations in Oklahoma. Northern Nut Growers Assn. 56:44 51.

Kuykendall, J.R. 1973. Tree-size control for high density plantings. Proc. Western Pecan Conf. 7:48-51.

Martin, G.C. 1971. Changing concepts in California walnut prodution. Proc. Southeastern Pecan Growers Assn. 64:47-58.

Ryugo, K., B. Marangoni, and D.E. Ramos. 1980. Light intensity and fruiting effects on carbohydrate contents, spur development, and return bloom of 'Hartley' walnut. J. Amer. Soc. Hort. Sci. 105:223-227.
Witt, H. J., J.R. Allison, and J.W. Daniell 1989. Economic analyses of space management practices in high-density pecan groves. J. Amer. Soc. Hort. Sci. 114:61-64.
Worley, R.E. 1984. Effect of pruning of three southeastern pecan cultivars. Proc. Southeastern Pecan Growers Assn. 77:105-108.

HORTSCIENCE 25(7):758-759. 1990.

\section{Sweetpotato Growth and Nitrogen Content Following Nitrogen Application and Inoculation with Azospirillum}

Desmond G. Mortley' and Walter A. Hill ${ }^{2}$

Department of Agricultural Sciences, Tuskegee University, Tuskegee, AL 36088

Additional index words. Ipomoea batatas, plant nutrition, nitrogen, fertilizers

Abstract. The influence of Azospirillum inoculation on sweetpotato Ipomoea batatas (L.) Lam.] was evaluated in combination with fertilizer $N$ rates of 0,40 , and $80 \mathrm{~kg}^{\mathrm{ha}}{ }^{-1}$. Plants were inoculated with $5 \mathrm{ml}$ of the inoculant at 2,4 , and 6 weeks after transplanting. Inoculation increased total and marketable yield by $12 \%$ and $17 \%$, respectively, in 1984 and $5 \%$ and $22 \%$, respectively in 1985 . Higher storage root yields were accompanied by lower foliage yields, which suggested the inoculant may enhance storage root growth at the expense of foliage growth on soils with low to moderate $\mathrm{N}$ levels $(40$ to $\left.80 \mathrm{~kg} \cdot \mathrm{ha}^{-1}\right)$. Storage root $N(1984$ and 1985) and leaf $N(1985)$ were higher for 40 $\mathrm{kg}$ N/ha with inoculation than with inoculation alone (treatments 4 vs. 2), which suggested that Azospirillum plus fertilizer $\mathbf{N}$ increased the $\mathbf{N}$ content of the plants.

$\mathrm{N}$-fixing bacteria are associated with roots of nonleguminous tropical and temperate plants. Nitrogen-15 incorporation and ${ }^{15} \mathrm{~N}$ isotope dilution methods have demonstrated $\mathrm{N}$ incorporation into several grass and cereal crops (Dobereiner and Pedrosa, 1987). Inoculation of cereal and grass crops with the $\mathrm{N}$-fixing bacteria Azospirillum results in increased plant growth, yield, and $\mathrm{N}$ concentration (Barber et al., 1979; Kapulnik et al., 1983; Millet et al., 1984), although results have been inconsistent (Dobereiner and Pedrosa, 1987). Crossman and Hill (1987) found that inoculation of sweetpotato with $\mathrm{Azo}$ spirillum increased $\mathrm{N}$ content, storage root yield, and foliage weight, depending on cultivar and inoculant strain used. Results from several studies suggest that Azospirillum may enhance plant growth by contributing growth hormones, such as cytokinins or auxins (Bouton et al., 1979, 1985; Tien et al., 1979). Our objective was to determine the effects of Azospirillum inoculation and $\mathrm{N}$ rates on storage root yield, foliage weight, and $\mathrm{N}$ content of sweetpotatoes.

Received for publication 15 May 1989. Contribution no. PS013 of the George Washington Carver Agricultural Experiment Station, CSRS/USDA, Project no. ALX-5P-1, Tuskegee Univ., Tuskegee, AL 36088. The cost of publishing this paper was defrayed in part by the payment of page charges. Under postal regulations, this paper therefore must be hereby marked advertisement solely to indicate this fact.

'Former Graduate Student. ${ }^{2}$ Professor.
Two experiments were conducted at the George Washington Carver Agricultural Experiment Station at Tuskegee Univ., Tuskegee, Ala., in 1984 and 1985. 'Centennial' sweetpotato slips were planted into Norfolk sandy loam (Typic Paleudult), previously limed to $\mathrm{pH} 6.5$, using $0.3-\mathrm{m}$ spacing within rows $1.2 \mathrm{~m}$ apart ( $\approx 29,000$ plants/ha). A completely randomized design with six treatments and four replications was used. The treatments consisted of three $\mathrm{N}$ levels $(0,40$, and $80 \mathrm{~kg} \cdot \mathrm{ha}^{-1}$ ) applied at planting (one half at planting, with the remainder applied 6 weeks thereafter for the highest rate) and combined with Azospirillum brasilense inoculum, no inoculum, or with an autoclave medium. The inoculum was applied manually into the root sorption zone of the same plants at 2, 4, and 6 weeks after transplanting. Each inoculation consisted of the application of $5 \mathrm{ml}$ of the bacterial suspension (TI-Sp-7, ATCC 35629) per plant at the rate of $10^{\mathrm{s}}$ to $10^{10} \mathrm{cells} / \mathrm{ml}$. Phosphorus and potassium were applied, based on soil tests, at 40 and $148 \mathrm{~kg} \cdot \mathrm{ha}^{-}{ }^{1}$, respectively. Field plots were not irrigated either year, but 1985 was a relatively dry growing season compared with 1984 (453 mm vs. $559 \mathrm{~mm})$.

The bacterial suspension was prepared by incubating a loopful of the bacteria in $20 \mathrm{ml}$ of a semisolid malate medium for $48 \mathrm{hr}$ at 30C. The chemical composition of the semisolid malate medium was similar to that of van Berkum (1980), and the $\mathrm{pH}$ of the medium was adjusted to 6.8 with $\mathrm{NaOH}$. The inoculum was prepared by quantitatively transferring the entire $20 \mathrm{ml}$ into the required 